\title{
Synthesis and evaluation of boronated chitosan as a mucoadhesive polymer for intravesical drug delivery
}

Article

Accepted Version

Creative Commons: Attribution-Noncommercial-No Derivative Works 4.0

Kolawole, O. M., Lau, W. M. and Khutoryanskiy, V. V. (2019) Synthesis and evaluation of boronated chitosan as a mucoadhesive polymer for intravesical drug delivery. Journal of Pharmaceutical Sciences, 108 (9). pp. 3046-3053. ISSN 0022-3549 doi: https://doi.org/10.1016/j.xphs.2019.05.006 Available at https://centaur.reading.ac.uk/83779/

It is advisable to refer to the publisher's version if you intend to cite from the work. See Guidance on citing.

To link to this article DOI: http://dx.doi.org/10.1016/j.xphs.2019.05.006

Publisher: Elsevier

All outputs in CentAUR are protected by Intellectual Property Rights law, including copyright law. Copyright and IPR is retained by the creators or other copyright holders. Terms and conditions for use of this material are defined in the End User Agreement.

www.reading.ac.uk/centaur 
Central Archive at the University of Reading

Reading's research outputs online 


\title{
Synthesis and evaluation of boronated chitosan as a mucoadhesive polymer for intravesical drug delivery
}

\author{
Oluwadamilola M. Kolawole, Wing Man Lau, Vitaliy V. Khutoryanskiy
}

a Reading School of Pharmacy, University of Reading, Whiteknights, PO Box 224, Reading, RG6 $6 A D$, Berkshire, United Kingdom

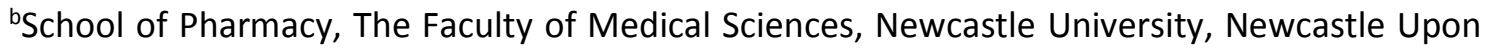
Tyne, NE1 7RU, United Kingdom

*Corresponding author: Prof V.V. Khutoryanskiy, Reading School of Pharmacy, University of Reading, Whiteknights, PO box 224, Reading, RG6 6AD, United Kingdom. Tel.: +44 (0) 118378 6119. E-mail address: v.khutoryanskiy@reading.ac.uk

This work reports the synthesis of boronated chitosan by reacting it with 4carboxyphenylboronic acid to improve its mucoadhesive properties. Three products with differing extent of boronate conjugation were synthesised and characterised using ${ }^{1} \mathrm{H}$ NMR, FTIR and UV-Vis spectroscopy and the potential of these polymers to extend the residence time of loaded model drug in the bladder was investigated. ${ }^{1} \mathrm{H}$ NMR and ninhydrin test were used to evaluate the extent of chitosan modification. Mucoadhesive properties were evaluated using ex vivo flow-through technique on porcine bladder mucosal tissue combined with fluorescent microscopy, where fluorescein sodium was used as a model drug. The mucoadhesive properties of these polymers on porcine bladder mucosa were also studied using tensile test. There was good correlation in the mucoadhesive profiles of the polymers using the flow through and tensile techniques. The degree of chitosan modification had a remarkable influence on their mucoadhesive behaviour and greater mucoadhesion was observed with increased degree of boronation. These chitosan derivatives have the potential as intravesical drug delivery systems to improve bladder therapy.

Keywords: Chitosan, Mucoadhesive, boronation, Intravesical drug delivery, bladder.

\section{Introduction}

Bladder cancer is one of the frequent causes of tumour-associated mortality worldwide and the overall survival tendency for the advanced stage of the disease is only about a year despite the fact that urothelial cancerous tissues respond well to conventional chemotherapeutic agents. ${ }^{1-}$ ${ }^{3}$ The local bioavailability and residence time of formulations delivered to the bladder is often 
reduced as drugs are diluted or washed out of the bladder due to urine filling and excretion. Thus there is a need to develop better mucoadhesive delivery systems that are resistant to urine wash out, thereby prolonging duration of drug action and preventing disease progression.

Chitosan is a biopolymer with well-established biodegradable, biocompatible and mucoadhesive properties. ${ }^{4-6}$ It is a polysaccharide consisting of acetylated and deacetylated glucosamine units, with the deacetylated segment that can be modified to prepare mucoadhesive derivatives such as chitosan-cysteine, ${ }^{7}$ chitosan-thioglycolic acid, ${ }^{8}$ chitosan-4thio-butyl-amidine ${ }^{9}$ chitosan-glutathione, ${ }^{10}$ chitosan- $\mathrm{N}$-acetylcysteine conjugates, ${ }^{11}$ chitosangraft-6-mercaptonicotinic acid ${ }^{12}$ and methacrylated chitosan. ${ }^{13}$

One of the constituents of mucosal membranes are mucin oligosaccharides, which have sialic acid groups that are overexpressed in malignant tissues and organs such as the bladder. ${ }^{14}$ So, sialic acid moieties have been explored as therapeutic targets by conjugating polymeric drug carriers with phenylboronic acid groups which bind favourably with sialic acid groups to form reversible covalent complexes, ${ }^{15}$ thereby facilitating enhanced mucoadhesion and cellular uptake of their therapeutic payload.

Phenylboronic acid decorated polymers have been explored for the delivery of drugs and biotherapeutics because they are biocompatible, mucoadhesive, can form stable colloidal systems and have tumour-targeting abilities. ${ }^{16-18}$ Transmucosal routes that have been explored include ocular, ${ }^{19-21}$ nasal ${ }^{22}$ and vaginal. ${ }^{23}$ Due to their responsiveness to glucose level, it makes them valuable for glucose detection ${ }^{18,24,25}$ and as glucose sensitive sustained insulin release system. ${ }^{26}$ They have also been explored for cancer targeting ${ }^{27-30}$ and gene delivery ${ }^{31,32}$ due to their favourable interaction with sialic acid moieties.

Liu et al demonstrated that cyclosporine loaded phenylboronic acid conjugated polymeric nanoparticles reduced ocular drug clearance. The boronated nanoparticles displayed good drug encapsulation efficiency $(13.7 \% \mathrm{w} / \mathrm{w})$, reduced inflammation after topical application to dryeye induced mice, and sustained drug release of up to 5 days showing their potential in reducing dosing interval and improving ocular drug bioavailability. ${ }^{20}$

Recently, in vivo studies using $\mathrm{H} 22$ lung metastasis tumour-bearing mice showed that doxorubicin loaded boronate modified chitosan nanoparticles exhibit greater antitumour activity than carboxymethyl chitosan nanoparticles. ${ }^{33} 3$ - and 4-carboxyphenylboronic acid modified chitosan nanoparticles were shown to exhibit superior doxorubicin loading, active 
tumor targeting, cellular internalisation and target site retention, relative to unmodified nanoparticles. ${ }^{33,34}$

Asantewaa et al studied the correlation between the physicochemical features of various boronic-acid-chitosan conjugates to their glucose adsorption properties. ${ }^{35}$ However, to our knowledge, there are no studies investigating how the physicochemical properties of different boronated chitosan affect urothelial mucoadhesiveness as a potential intravesical dosage form for bladder cancer treatment. Thus there is a critical need to establish whether boronated chitosan has sufficient interaction with the urothelial mucosa that is constantly in contact with urine, to prolong drug residence time in the bladder.

In this work, we synthesised boronate-conjugated chitosan derivatives by reaction of chitosan with 4-carboxyphenylboronic acid using EDC and NHS as coupling agents, characterised the resultant products in terms of their physicochemical properties and evaluated in vitro adhesion to porcine urinary bladder mucosa to establish their intravesical drug delivery potential.

\section{Materials and Methods}

\subsection{Materials}

Chitosan (high molecular weight grade, $370 \mathrm{kDa}$; degree of acetylation extent $29.3 \pm 2.5 \%$ ), ninhydrin, trifluoroacetic acid, FITC-dextran (3-5 kDa), dextran $5 \mathrm{kDa}$, deuterium oxide, urea, uric acid, magnesium sulphate heptahydrate, sodium hydrogen phosphate, creatinine, sodium bicarbonate, sodium sulphate, disodium oxalate and trisodium citrate were all purchased from Sigma-Aldrich, UK. 4-carboxyphenylboronic acid (4-CPBA), N-3(dimethylaminopropyl)-Nethylcarbodiimide hydrochloride (EDC), N-hydroxysuccinimide (NHS), dimethyl sulfoxide (DMSO), disodium hydrogen phosphate, sodium chloride, potassium chloride, ammonium chloride and calcium chloride dihydrate were all purchased from Fisher Scientific, UK. Dialysis membrane with molecular weight cut off 12-14 kDa was obtained from Medicell International, UK. All chemical reagents were used as received without further purification. Freshly excised porcine urinary bladders were procured from PC Turner Abattoir (Farnborough, Hampshire, UK).

\subsection{Synthesis of boronated chitosan}

Three types of boronated chitosan were synthesised by varying the molar amount of 4-CPBA (Table 1) using a published method with modification. ${ }^{34}$ 
Briefly, $1.5 \% \mathrm{w} / \mathrm{v}$ chitosan solution $(100 \mathrm{~mL}$ ) was prepared in $4 \% \mathrm{v} / \mathrm{v}$ acetic acid for $12 \mathrm{~h}$ at room temperature for complete polymer dissolution. According to Table 1, the required amounts of 4-CPBA, EDC and NHS were dissolved in predetermined amounts of DMSO, stirred under dark conditions at room temperature for $30 \mathrm{~min}$. The 4-CPBA/NHS/EDC mixtures were then added slowly to chitosan solution and stirred for another $24 \mathrm{~h}$ at room temperature, in the dark. The products were redispersed in deionised water, purified by dialysis in the dark (MWCO 12-14 kDa membrane) against $4.5 \mathrm{~L}$ of $7 \mathrm{mM} \mathrm{HCl}$ for $24 \mathrm{~h}$ (three changes) followed by dialysis against $4.5 \mathrm{~L}$ deionised water for 2 days ( 6 changes) to remove unreacted 4-CPBA. The products were freezedried using Heto PowerDry LL3000 Freeze Dryer (Thermo Scientific, UK).

Table 1

Materials used for the synthesis of boronated chitosan, with low (LBCH), medium (MBCHI) and high (HBCHI) degrees of modification.

\begin{tabular}{llll}
\hline Parameters & LBCHI & MBCHI & HBCHI \\
\hline Chitosan (CHI) concentration (\% w/v) & 1.5 & 1.5 & 1.5 \\
4-carboxyphenyl boronic acid (4-CPBA, g) & 0.28 & 0.56 & 1.11 \\
$\begin{array}{l}\text { N-3(dimethylaminopropyl)-N-ethylcarbodiimide } \\
\text { hydrochloride (EDC, g) }\end{array}$ & 0.39 & 0.77 & 1.54 \\
N-hydroxysuccinimide (NHS, g) & 0.23 & 0.47 & 0.93 \\
DMSO for 4-CPBA, EDC \& NHS dissolution (mL) & 5 & 10 & 20 \\
Moles of 4-CPBA per unit mole CHI & 0.20 & 0.39 & 0.79 \\
\hline
\end{tabular}

\subsection{Characterisation of boronated chitosan}

\subsection{1. ${ }^{1} \mathrm{H}$ NMR spectroscopy}

Solutions of $\mathrm{CHI}, \mathrm{LBCHI} \mathrm{MBCHI}$, and $\mathrm{HBCHI}(0.6 \% \mathrm{w} / \mathrm{v})$ were prepared in $\mathrm{D}_{2} \mathrm{O}$ acidified with $30 \mu \mathrm{L}$ trifluoroacetic acid and allowed to be dissolved overnight at room temperature. The ${ }^{1} \mathrm{H}$ NMR spectra were recorded using $400 \mathrm{MHz}$ Ultrashield Plus ${ }^{\mathrm{TM}}$ B-ACS 60 spectrometer (Bruker, UK). 


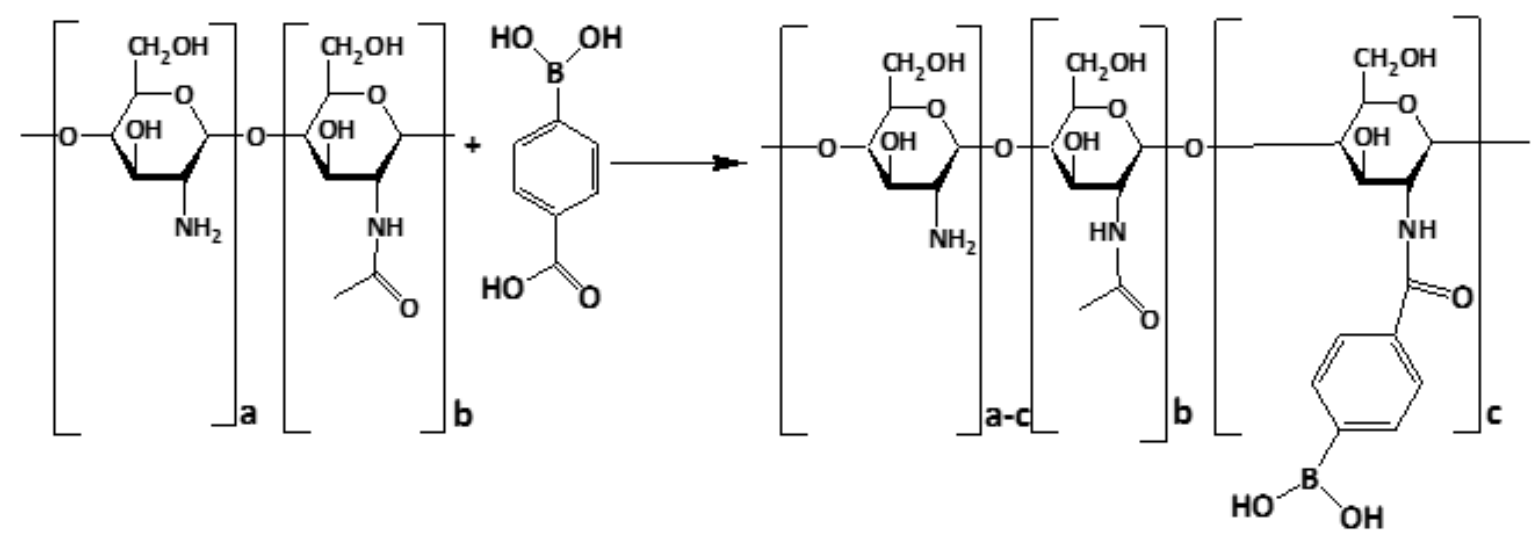

\section{CHI 4-CPBA LBCHI or MBCHI or HBCHI}

Fig. 1. Reaction scheme for the synthesis of boronated chitosan: $\mathrm{CHI}$ is the parent chitosan and LBCHI, $\mathrm{MBCHI}$, and $\mathrm{HBCHI}$ are chitosans with low, medium, and high degrees of boronation, respectively; a (deacetylated), b (acetylated), and c (boronated) segments of chitosan repeating units.

\subsubsection{Quantification of the extent of chemical modification}

The quantity of boronate groups conjugated to chitosan was calculated using previously published method with slight modification. ${ }^{36}$ Briefly, $2 \% \mathrm{w} / \mathrm{v}$ solution of ninhydrin in DMSO was prepared by stirring for $12 \mathrm{~h}$, protected from light at room temperature. Unmodified and modified chitosan solutions $(0.05-0.5 \% \mathrm{w} / \mathrm{v})$ were prepared by dissolving in $0.1 \mathrm{M}$ acetic acid, stirred for $12 \mathrm{~h}$ under dark conditions at room temperature. $5 \mathrm{~mL}$ of ninhydrin solution and 1.25 $\mathrm{mL}$ of $4 \mathrm{M}$ phosphate buffer $(\mathrm{pH} 5.4 \pm 0.2)$ were mixed with $0.5 \mathrm{~mL}$ polymer solution. The resultant mixtures were incubated in a water bath at $85^{\circ} \mathrm{C}$ shaken at $60 \mathrm{rpm}$ for $30 \mathrm{~min}$. The degree of chitosan amine substitution was determined using microplate spectrophotometer at $500 \mathrm{~nm}$ (Epoch, BioTek Instruments Inc., UK). Mixture of ninhydrin solution and phosphate buffer solution (4M, pH 5.4) (4:1) served as the blank control.

\subsubsection{Fourier Transform-Infrared spectroscopy (FT-IR)}

Solid samples of modified and unmodified chitosan were scanned from 4,000 to $600 \mathrm{~cm}^{-1}$, resolution of $4 \mathrm{~cm}^{-1}$ to identify characteristic functional groups in both chitosan and the boronate moieties that suggested that boronation was successful. Data was processed based on the average of sixteen scans per spectrum generated by FT-IR spectrometer (PerkinElmer Spectrum 100, Thermo Scientific, UK). 


\subsubsection{Turbidimetric analysis}

The influence of $\mathrm{pH}$ on the turbidity of polymer samples was evaluated based on a method reported by Sogias et al. (2010) with slight modification. ${ }^{37}$ Briefly, polymer solutions $(0.1 \% \mathrm{w} / \mathrm{v}$, $\mathrm{pH} 3$ ) were prepared in $0.1 \mathrm{M}$ acetic acid at room temperature. $\mathrm{NaOH}$ solution $\left(0.1 \mathrm{~mol} \cdot \mathrm{L}^{-1}\right)$ was added to increase the $\mathrm{pH}$ stepwise from 3 to 9 and $0.1 \mathrm{~mol} \cdot \mathrm{L}^{-1} \mathrm{HCl}$ was used to adjust the $\mathrm{pH}$ of the samples if necessary. The turbidity values of polymer dispersions were measured at $400 \mathrm{~nm}$ using UV-Vis spectrophotometer (Jenway 7315, Bibby Scientific, UK).

\subsubsection{X-ray diffraction analysis}

In order to investigate the influence of boronation on the crystallinity of chitosan, solid forms of the polymers were studied using an earlier reported method..$^{13}$ Briefly, solid samples of $\mathrm{CHI}$, $\mathrm{LBCHI}, \mathrm{MBCH}$, and $\mathrm{HBCH}$ were loaded into a capillary tube sealed with wax to avoid loss of sample and placed onto the goniometer under a microscope to be analysed with a wide-angle powder D8 Advance diffractometer/LYNXEYE XE detector (Bruker, UK). Samples were scanned at diffraction ranges from 5 to $65^{\circ} \mathrm{C}$ with a scan step of $0.02^{\circ}$, producing distinctive diffractograms at the rate of 2.5 scans min $^{-1}$.

\subsection{Ex vivo porcine mucoadhesion studies}

\subsubsection{Preparation of polymer / fluorescein sodium mixtures and artificial urine solutions}

The solutions/dispersions of $\mathrm{CHI}, \mathrm{LBCHI}, \mathrm{MBCH}$ and $\mathrm{HBCH}$ were prepared by dissolving the polymers in $0.1 \mathrm{M}$ acetic acid and stirred overnight in dark conditions at room temperature. Resultant polymer solutions/dispersions were mixed with $0.1 \% \mathrm{w} / \mathrm{v}$ fluorescein sodium to yield final polymer concentration of $0.4 \% \mathrm{w} / \mathrm{v}(\mathrm{FS} / \mathrm{CHI}, \mathrm{FS} / \mathrm{LBCHI}, \mathrm{FS} / \mathrm{MBCH}$ and $\mathrm{FS} / \mathrm{HBCHI}$, respectively). FITC-dextran $0.4 \% \mathrm{w} / \mathrm{v}$ in deionised water served as negative control.

Chutipongtanate and Thongboonkerd (2010) method $^{38}$ was used to prepare artificial urine. Briefly, urea (24.27 g), uric acid (0.34 g), magnesium sulphate heptahydrate (1.00 g), sodium hydrogen phosphate $(1.00 \mathrm{~g})$, disodium hydrogen phosphate $(0.11 \mathrm{~g})$, creatinine $(0.90 \mathrm{~g})$, sodium bicarbonate $(0.34 \mathrm{~g})$, sodium sulphate $(2.58 \mathrm{~g})$, disodium oxalate $(0.03 \mathrm{~g})$, trisodium citrate $(2.97 \mathrm{~g})$, sodium chloride $(6.34 \mathrm{~g})$, potassium chloride $(4.50 \mathrm{~g})$, ammonium chloride (1.61 $\mathrm{g})$, and calcium chloride dihydrate $(0.89 \mathrm{~g}$ ) were dissolved in $2 \mathrm{~L}$ ultrapure water $(18.2 \mathrm{M} \Omega$ ) for $3 \mathrm{~h}$ at room temperature. The resultant artificial urine had a final $\mathrm{pH}$ of $6.2 \pm 0.2$. 


\subsubsection{Retention on porcine urinary bladder mucosa}

Fluorescence microscopy (MZ10F microscope, Leica Microsystems, UK), coupled to an "ET GFP" filter camera (Zeiss Imager A1/AxioCam MRm camera, 1296 x 966 pixels, 0.8 x magnification) was used to investigate the mucosal retention of model drug fluorescein sodium in the presence of the polymeric carriers based on a slightly modified protocol developed in-house. ${ }^{39}$ Freshly excised porcine urinary bladders were stored on ice until use and used within $24 \mathrm{~h}$ of procurement. The mucosal side of the bladder tissue was prevented from any possible damage during excision of the studied mucosal section about $1.5 \times 2.5 \mathrm{~cm}$ and rinsed with artificial urine solution ( $3 \mathrm{~mL}$ ) prior to blank tissue imaging. The bladder tissue was placed on a glass slide and maintained in an incubator at $37^{\circ} \mathrm{C}$ during urine wash-out. The following exposure times were used: FITC-dextran (80 ms), FS/CHI (211 ms), FS/LBCHI, FS/MBCHI and FS/HBCHI (86 ms). Microscopic images of the tissues were taken before and after sample application $(50 \mu \mathrm{L})$ as well as after each of the five washing cycles with $10 \mathrm{~mL}$ artificial urine/cycle at $2 \mathrm{~mL} / \mathrm{min}$. The studies were carried out in triplicates. Image J software (National Institute of Health, USA) was used to analyse the microscopic images, generating average fluorescence values as a function of urine volume used for the wash-out. Fluorescence intensity values were normalised against the blank tissue control. The $\mathrm{WO}_{50}$ values (volume of artificial urine required to wash-out $50 \%$ of the applied fluorescence sodium/polymer mixture) were determined based on the polynomial fit of the percent mucosal fluorescence retention versus artificial urine volume graphs (Fig. S1, Supplementary information).

\subsection{Tensile method}

The TA-XT Plus Texture Analyser (Stable Micro Systems Ltd, UK) coupled to a $5 \mathrm{~kg}$ load cell was used as an additional technique to study the mucoadhesive properties of the polymer samples. Blank chitosan solutions ( $0.4 \% \mathrm{w} / \mathrm{v}$ in $0.1 \mathrm{M}$ acetic acid solution) served as the positive control, while the negative control was dextran solution ( $0.4 \% \mathrm{w} / \mathrm{v}$ in water). Porcine bladder tissues were secured at the base of a cylindrical container. The vessel bottom had a circular cut-out region (20 mm diameter) exposing the mucosal surface of the bladder tissue. This container was screwed onto the probe of the texture analyser through a hole drilled on the lid of the container. Another bladder tissue was placed on a petridish and coupled onto the lower platform of the texture analyser, exposing the mucosal surface $(20 \mathrm{~mm}$ diameter) of another bladder tissue. The tests were performed using an earlier reported equipment settings ${ }^{40}$ with slight modification: pre-speed test $1.0 \mathrm{~mm} / \mathrm{s}$; test speed $0.1 \mathrm{~mm} / \mathrm{s}$; post-test speed $0.1 \mathrm{~mm} / \mathrm{s}$; applied force $0.05 \mathrm{~N}$; contact time $120.0 \mathrm{~s}$; trigger type auto; trigger force $0.1 \mathrm{~N}$; and return distance of $10.0 \mathrm{~mm}$. 
Bladder tissues were maintained in an incubator at $37^{\circ} \mathrm{C}$ for 5 min prior to the study. $\mathrm{CHI}$, dextran, $\mathrm{LBCHI}, \mathrm{MBCH}$ and $\mathrm{HBCH}$ samples $(0.4 \mathrm{~mL})$ were applied onto the exposed area of the bladder tissue secured onto the lower platform of the texture analyser. The probe was then lowered such that the upper blank bladder tissue comes in contact with the formulation applied onto the bladder tissue secured on the lower platform for $2 \mathrm{~min}$. The Texture Analyser software (T.A. Exponent) was used to record the area under the force versus distance curves (work of adhesion) as well as the force of adhesion/adhesive strength which is the maximum force needed to detach tissue from the polymer solutions/dispersions. ${ }^{40,41}$

\subsection{Statistical analysis}

All experimental data were collected in triplicates and data expressed as mean \pm standard deviation. Data were compared using t-test and one-way ANOVA/post-hoc Bonferroni test with GraphPad Prism 5.04 (GraphPad Software Inc., San Diego, California), with $p<0.05$ depicting significant statistical difference between data sets.

\section{Results and discussion}

The potential for chitosan as material for drug delivery and tissue engineering cannot be overemphasised due to its physical and biological properties such as biocompatibility, mucoadhesiveness and permeation enhancing properties., ${ }^{5,42-44}$ Chemical modification of chitosan with boronate groups may impact on its urothelial mucoadhesiveness. The biocompatible nature of boronate modified chitosan nanoparticles has been previously established in mouse and mammalian cells. ${ }^{33,34}$ Over $90 \%$ of human bone marrow neuroblastoma SH-SY5Y cells, human liver cancer HepG2 cells and mouse liver cancer $\mathrm{H} 22$ cells remained viable after incubation with chitosan and boronated chitosan based nanoparticles for 48h. ${ }^{34}$ Also, boronated dextran based formulations were tested on healthy rabbit eyes and did not trigger any inflammatory response acutely (1 week) and chronically (12 weeks). ${ }^{20}$ These studies suggested that boronated drug carriers are safe. Consequently, cytotoxicity testing was not carried out for the studied boronated chitosan. Moreover, several in vitro and in vivo studies have already established the safety of phenylboronate molecules. ${ }^{17,20,45}$

\subsection{Synthesis of boronated chitosan derivatives and physical properties}

Three types of boronated chitosan were synthesised (Table 1) using EDC/NHS chemistry which is an efficient synthetic method for covalent amide bond formation. ${ }^{46}$ The yields of LBCHI, $\mathrm{MBCHI}$, and $\mathrm{HBCHI}$ were $61 \%, 43 \%$, and $33 \%$, respectively and all materials were off white colour 
(Table 2). The product yield decreased as the extent of chitosan modification increased. This finding correlates well with our previous studies where chitosan with low extent of methacrylation produced a greater yield (62\%) than sample with a high extent of methacrylation (24\%). ${ }^{13}$ The potential reacetylation of chitosan with acetic acid under the conditions of the reaction does not happen as it is seen from the analysis of acetylation degrees of all products, which do not change significantly.

Table 2

Yield and degrees of boronation (using ${ }^{1} \mathrm{H}$ NMR spectroscopy and ninhydrin test) and acetylation (using $1 \mathrm{H}$ NMR spectroscopy) of $\mathrm{LBCHI}, \mathrm{MBCHI}$, and $\mathrm{HBCHI}$

\begin{tabular}{|l|l|l|l|l|}
\hline Parameter & Chitosan & LBCHI & MBCHI & HBCHI \\
\hline Yield (\%) & n/a & 61 & 43 & 33 \\
\hline $\begin{array}{l}\text { Boronation extent } \\
\text { (\%) } \\
{ }^{1} \text { H NMR }\end{array}$ & n/a & $3.9 \pm 0.3$ & $5.5 \pm 0.1$ & $16.5 \pm 0.2$ \\
Ninhydrin test & n/a & $4.4 \pm 1.8$ & $7.4 \pm 1.2$ & $10.7 \pm 2.2$ \\
\hline Acetylation (\%) & $29.3 \pm 2.5$ & $26.6 \pm 1.0$ & $29.4 \pm 0.9$ & $31.8 \pm 1.5$ \\
\hline
\end{tabular}

According to the ${ }^{1} \mathrm{H}$ NMR spectra (Fig. 2), the characteristic peaks of chitosan were evident at $2.0 \mathrm{ppm}\left(-\mathrm{CH}_{3}\right.$ from the acetylated segment of chitosan) as well as 3.1-3.8 ppm (protons from the glucosamine ring). With the boronated chitosan, additional peaks were evident at 7.8-8 ppm representative of the phenyl ring protons from the boronate moiety, confirming the successful conjugation of phenylboronate groups to chitosan. Also, the peaks at 2.7-2.8 ppm for the boronated chitosan are the result of the quartet methyne protons of the boronic acid. These spectral data are in good agreement with that reported by Zhang et al. ${ }^{14}$ 


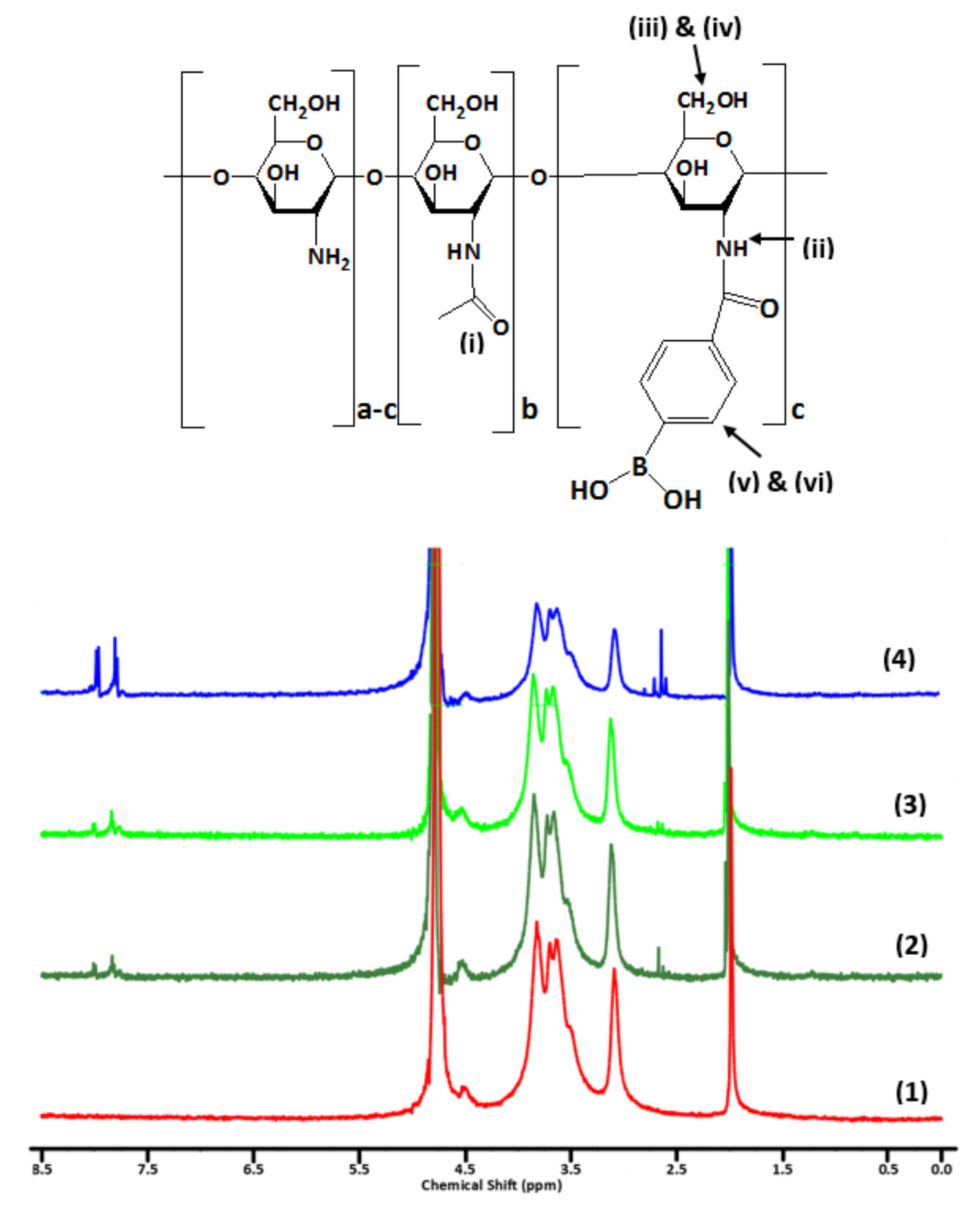

Fig. 2. ${ }^{1} \mathrm{H}$ NMR spectra of $\mathrm{CHI}(1), \mathrm{LBCHI}(2), \mathrm{MBCHI}(3)$, and $\mathrm{HBCHI}$ (4), recorded in $\mathrm{D}_{2} \mathrm{O}$ acidified with $1 \%$ trifluoroacetic acid. Methyl protons from the acetylated part of chitosan observed at $2.0 \mathrm{ppm}$ (i), methyne protons from the boronate moiety were evident at $2.7-2.8$ ppm; (ii) $\mathrm{H} 2-\mathrm{H} 6$ protons of $\mathrm{CHI}$ were detected at 3.0-4.0 ppm (iii \& iv) and benzene ring of the boronate groups detected around 7.8 and $8.0 \mathrm{ppm}(\mathrm{v} \&$ vi). 
Their degree of boronation was calculated from the ratio of mean intensity of the proton peaks of the boronate moieties $(\delta=7.8-8.0 \mathrm{ppm})$ relative to that of the chitosan glucosamine protons $(\delta=3.0-4.0 \mathrm{ppm})$.

Boronation $(\%)=\frac{\text { Integral of boronate protons at } 7.8 \& 8.0 \mathrm{ppm} / 2}{\text { Integral of chitosan } \mathrm{H} 2-\mathrm{H} 6 \text { protons } / 6} \cdot 100 \%$

Based on ${ }^{1} \mathrm{H}$ NMR data analysis (Fig. S1), a two-fold increase in the ratio of 4-CPBA per unit mole of chitosan used for LBCHI to generate MBCHI (Table 1) did not show a doubling of boronate conjugation (3.9\% vs 5.5\%, respectively) despite doubling the amount of boronate groups available to conjugate with the chitosan primary amino group. However, a 3-fold increase in the degree of boronation occurred when doubling the quantity of 4-CPBA in $\mathrm{HBCHI}$ against $\mathrm{MBCHI}$ with boronation of $5.5 \%$ and $16.5 \%$, respectively. This finding may be due to a critical amount of 4-CPBA required to conjugate boronate groups to chitosan amine groups significantly.

\subsection{Calculation of boronation extent using ninhydrin test}

The ninhydrin test was used as an additional means of quantifying the degree of substitution of chitosan amine groups with boronate moieties. The principle of detection is based on the fact that ninhydrin reacts with the unmodified amine groups of chitosan to form a coloured product measurable by UV spectroscopy. ${ }^{47}$ The slope of the adsorption versus concentration curve of unconjugated chitosan is represented as $\delta_{\mathrm{CH}}$, while that of $\mathrm{LBCHI}, \mathrm{MBCH}$, and $\mathrm{HBCHI}$ are denoted as $\delta_{\mathrm{BCH}}$. Boronation percentage can be defined as $\left(1-\delta_{\mathrm{BCH}} / \delta_{\mathrm{CHI}}\right) * 100 \%$. ${ }^{13,36} \mathrm{The}$ respective boronation extent for $\mathrm{LBCHI}, \mathrm{MBCHI}$, and $\mathrm{HBCH}$ were $4.4 \%, 7.4 \%$, and $10.7 \%$ (Table 2). These values were comparable with that calculated using ${ }^{1} \mathrm{H}$ NMR spectroscopy $(3.9 \%, 5.5 \%$, and $16.5 \%$, respectively) and showing the same trend in the degree of boronation with an increase in the molar ratio of 4-CPBA used.

\subsection{FT-IR analysis}

FT-IR spectra (Fig. 3) showed pronounced absorption band at 1026-1151 $\mathrm{cm}^{-1}$ indicating the amine C-N stretch from chitosan. Since both chitosan and boronate groups exhibit alkyl C-H stretch at 2850 and $2930 \mathrm{~cm}^{-1}$, the increase in the intensity of the absorption bands depicts the formation of the boronated chitosan. The appearance of the new signal at $1311 \mathrm{~cm}^{-1}$ indicated $-\mathrm{B}(\mathrm{OH})_{2}$ groups of the boronic acid segment and peaks evident at 713 and $1533 \mathrm{~cm}^{-1}$ represented para-substituted benzene ring. The prominent absorption peak at $1636 \mathrm{~cm}^{-1}$ in $\mathrm{LBCHI}, \mathrm{MBCHI}$ and $\mathrm{HBCHI}$ confirmed the successful grafting of phenylboronate groups onto chitosan. This finding is in good agreement with the FT-IR spectra chitosan-boronate conjugate 
reported in earlier studies ${ }^{14}$ where $-\mathrm{B}(\mathrm{OH})_{2}$ groups were evident at $1333 \mathrm{~cm}^{-1}$; aromatic $\mathrm{C}-\mathrm{H}$ bending bands were observed at $713 \mathrm{~cm}^{-1}$ while that of the benzene ring appeared at $1546 \mathrm{~cm}^{-}$ ${ }^{1}$. Also, the absorption peak confirming chitosan boronation $\left(1636 \mathrm{~cm}^{-1}\right)$ is comparable to that of the chitosan-boronate conjugate earlier reported $\left(1643 \mathrm{~cm}^{-1}\right)$. The FT-IR spectra of LBCHI, $\mathrm{MBCHI}$ and $\mathrm{HBCHI}$ are comparable but vary in terms of the spectral intensity, which is dictated by their degree of boronation.

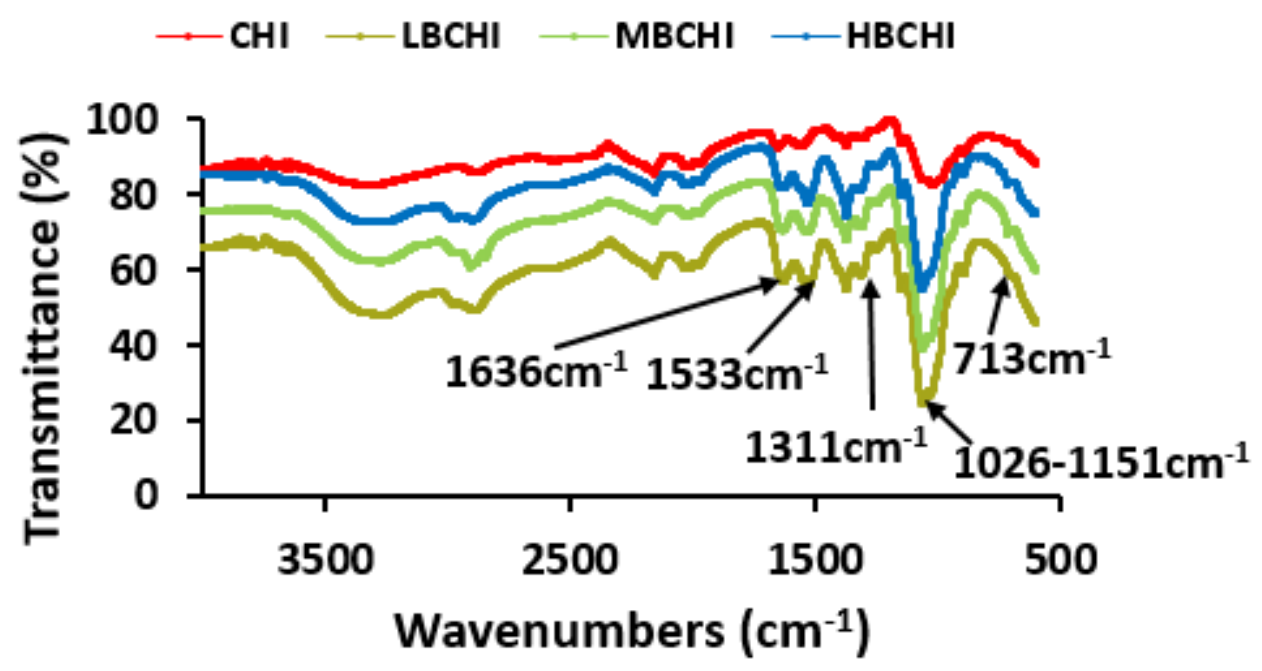

Fig. 3. FT-IR spectra of chitosan and boronated chitosan with distinct peak at $1311 \mathrm{~cm}^{-1}$ indicative of $\mathrm{B}(\mathrm{OH})_{2}$ groups; absorption bands at 713 and $1533 \mathrm{~cm}^{-1}$ depicted p-substituted benzene and absorption band confirming - NH-CO- linkage between chitosan and boronate groups evident at $1636 \mathrm{~cm}^{-1}$.

\subsection{Turbidimetric analysis}

The typical $\mathrm{pH}$ of the bladder environment is between 6 and 7. However, various factors such as diet and disease states such as bladder cancer can impact urine $\mathrm{pH}$ resulting in $\mathrm{pH}$ ranges from 4.6 to $8{ }^{48-50}$ Moreover, changes in solution turbidity may impact product stability and performance. Thus there is a need to develop drug carriers that will withstand possible $\mathrm{pH}$ changes in the bladder.

The modified and unmodified chitosan solutions maintained transparency until pH 6.5, where further increase in $\mathrm{pH}$ resulted in a drastic increase in solution turbidity (Fig. 4). This turbidity$\mathrm{pH}$ pattern is in good agreement with our earlier reports, ${ }^{13,37}$ where the unmodified chitosan and the chitosan with low extent of methacrylation displayed steep increase in degree of turbidity at $\geq \mathrm{pH} 6.5$ comparable to our boronated chitosans. The influence of boronate conjugation on the turbidity of chitosan solution was pronounced at $\mathrm{pH} \geq 7$, where the boronated chitosans displayed a lower turbidity than that of the unmodified chitosan $(p<0.05)$. 
This is because at $\mathrm{pH} \geq 7$ and higher degree of boronate conjugation, the bulky boronate groups would disrupt the semi-crystalline nature of chitosan, thereby improving its solubility and decreasing the solution turbidity. ${ }^{13,37}$ There was significant difference in the turbidity values of the boronated chitosan at $\mathrm{pH} 9$ (Fig. 4).

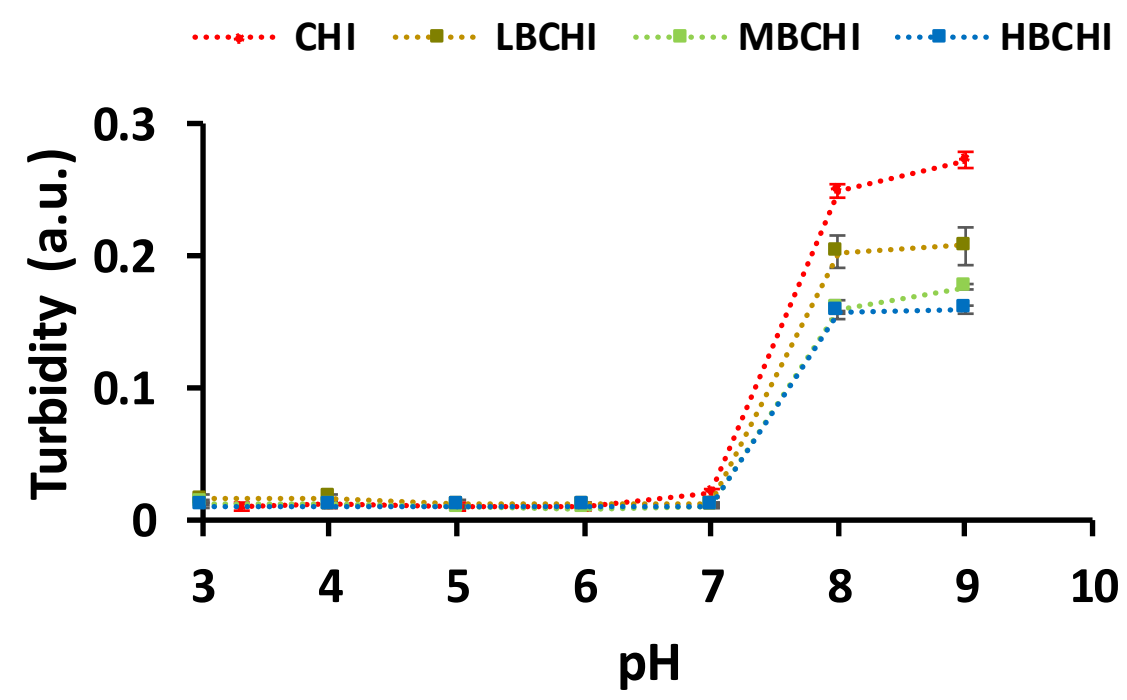

Fig. 4. Effect of $\mathrm{pH}$ on solution turbidity of unmodified and boronated chitosan $(n=3$, mean \pm standard deviation)

\subsection{X-ray diffraction analysis}

Chitosan is a semi-crystalline polymer that displayed two main peaks at diffraction angles of $9.8^{\circ}$ and $20.5^{\circ}$ (Fig. 5). This finding is in good agreement with that of the chitosan peaks we previously reported. ${ }^{13,37,51,52}$ There was reduction in the crystallinity of chitosan after boronation with the disappearance and broadening of peaks as well as peaks appearing at a diffraction angle different from that of chitosan. The boronated chitosan did not exhibit any peak at a diffraction angle of $9.8^{\circ}$. The distinctive broad peaks for $\mathrm{LBCHI}, \mathrm{MBCH}$ and $\mathrm{HBCHI}$ were evident at $20.5^{\circ}$, $21.6^{\circ}$ and $21.9^{\circ}$, respectively (Fig. 5). This finding is in good agreement with that observed with the methacrylated chitosans with loss and broadening of peaks evident at diffraction angles of $8.3^{\circ}$ and $22.4^{\circ}$, respectively..$^{13}$ 


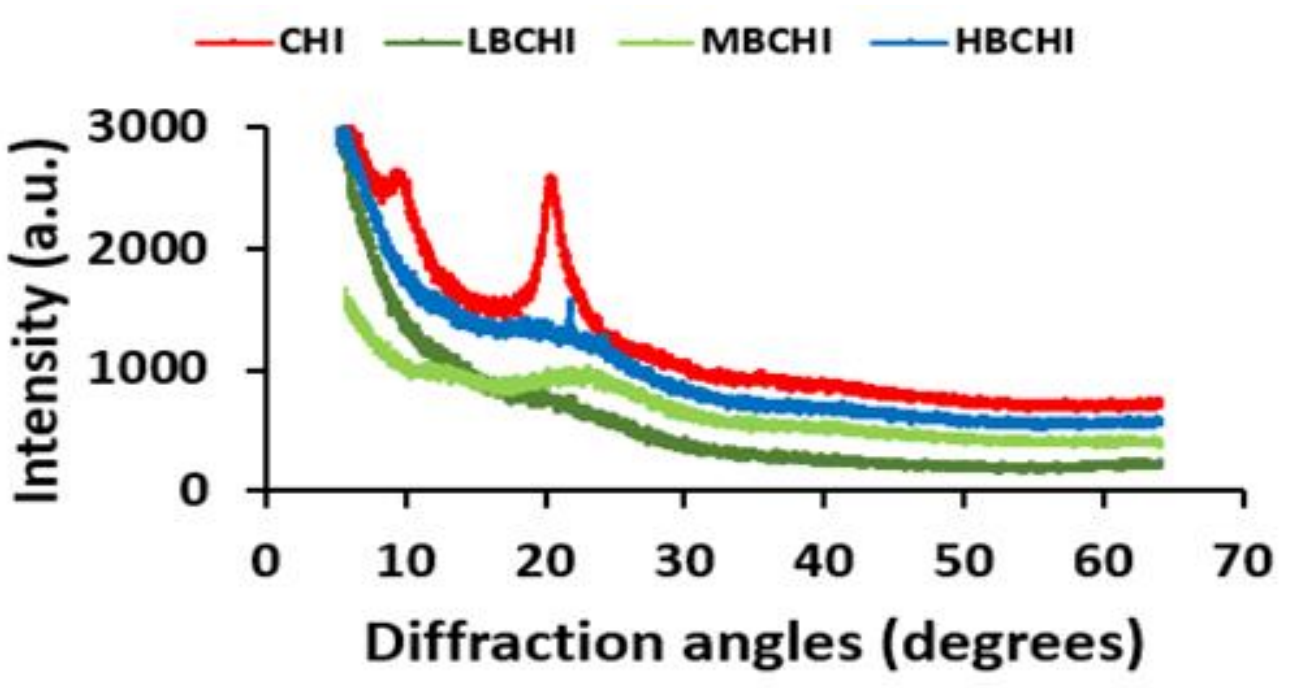

Fig. 5. X-ray diffractograms of $\mathrm{CHI}, \mathrm{LBCHI}, \mathrm{MBCHI}$ and $\mathrm{HBCHI}$ generated at scan angle 5-65 ${ }^{\circ}, 2.5$ scans.min1 , scan step of $0.02^{\circ}$, spectra offset for improved clarity.

\subsection{Urine wash-out studies}

Fluorescein sodium (FS), which served as the model drug, was mixed with the unmodified and boronated chitosan prior to the mucoadhesion studies. The unmodified chitosan served as the mucoadhesive positive control, ${ }^{53}$ while the negative control was FITC-dextran, with limited mucoadhesive property. ${ }^{54}$ The ex vivo porcine bladder was used to measure the wash-out 50 values of fluorescein sodium in the presence of the unmodified and boronated chitosan. $\mathrm{WO}_{50}$ is the volume of artificial urine needed to remove $50 \%$ of fluorescein from the bladder mucosal surface. ${ }^{39}$

FITC-dextran displayed the least mucosal retention on the porcine bladder mucosa $\left(\mathrm{WO}_{50}\right.$ of $7 \pm 2$ $\mathrm{mL}$, Fig. 6) from extrapolation as $10 \mathrm{~mL}$ of artificial urine was used for each wash-out cycle similar to that reported previously. ${ }^{13,39}$ FITC-dextran was significantly less mucoadhesive than the boronated chitosan over the five washing cycles (with $50 \mathrm{~mL}$ artificial urine) $(p<0.05)$. Also, unmodified chitosan was significantly more mucoadhesive than FITC-dextran $(p<0.05)$.

Typically, cationic polymers like chitosan interact with negatively charged sialic acid groups present on urothelial mucosal surfaces via electrostatic interaction. Phenylboronic acid is composed of phenyl substituent and two hydroxyl groups attached to boron, which enables it to form a complex with the diol groups of sialic acid at physiological $\mathrm{pH} .{ }^{15}$ The presence of counter ions in the artificial urine used for the wash-out studies inhibits the favourable interaction of chitosan with sialic acid-rich mucosal surfaces. Chitosan conjugation with boronate groups $(\mathrm{HBCHI})$ resulted in 3.1-fold increase in their $\mathrm{WO}_{50}$ values. The $\mathrm{WO}_{50}$ values of 
$\mathrm{FS} / \mathrm{CHI}, \mathrm{FS} / \mathrm{LBCHI}, \mathrm{FS} / \mathrm{MBCHI}$ and $\mathrm{FS} / \mathrm{HBCHI}$ were $15 \pm 4 \mathrm{~mL}, 23 \pm 3 \mathrm{~mL}, 48 \pm 5 \mathrm{~mL}$ and $55 \pm 2 \mathrm{~mL}$, respectively, calculated based on the polynomial fit of the mucosal fluorescence retention versus urine volume graph (Fig. S2). Boronated chitosan may interact with mucosal surfaces through various mechanisms:22 (i) the phenylboronic acid groups could potentially form covalent linkage with sialic acid expressed on cell membranes to form reversible covalent complexes $^{55,56}$, (ii) hydrogen bond formation with mucin glycoproteins possible due to its constituent hydroxyl groups ${ }^{43}$ and (iii) electrostatic interaction between cationic polymer and negatively charged sialic acid residues. ${ }^{42,53}$ Therefore, the greater degree of mucoadhesion as seen in $\mathrm{HBCH}$ could be due to the more boronate groups being available to interact with the mucosal surface (Fig. 6 and Fig. 7).

Significant difference in the mucoadhesive behaviour of the parent chitosan and the boronated derivatives ( $\mathrm{LBCHI}, \mathrm{MBCHI}$ and $\mathrm{HBCHI}$ ) can be seen after two urine washing cycles and differences remained significant after five washing cycles $(p<0.05)$. MBCHI and $\mathrm{HBCHI}$ were significantly more mucoadhesive than $\mathrm{LBCHI}$ after the first washing cycle with $10 \mathrm{~mL}$ artificial urine. On the other hand, the mucoadhesive behaviour of $\mathrm{MBCHI}$ and $\mathrm{HBCHI}$ was not significantly different after 5 washing cycles with $50 \mathrm{~mL}$ artificial urine. This finding indicated that the urine wash-out resistance of boronated chitosan may become unchanged after a certain degree of boronation. Fig. 7 confirmed that FS/CHI and FS/LBCHI displayed comparable mucoadhesiveness in terms of their $\mathrm{WO}_{50}$ values $(15 \pm 4 \mathrm{~mL}$ vs $23 \pm 3 \mathrm{~mL}$ ) but that of $\mathrm{HBCHI}$ was significantly more mucoadhesive than $\mathrm{MBCH}$, with $\mathrm{WO}_{50}$ values of $48 \pm 5 \mathrm{~mL}$ and $56 \pm 2 \mathrm{~mL}$, respectively. Thus, boronation still had a somewhat influence on the mucoadhesiveness of the boronated chitosans, which was most prominent after washing out the bladder mucosa with 30 $\mathrm{mL}$ artificial urine. 


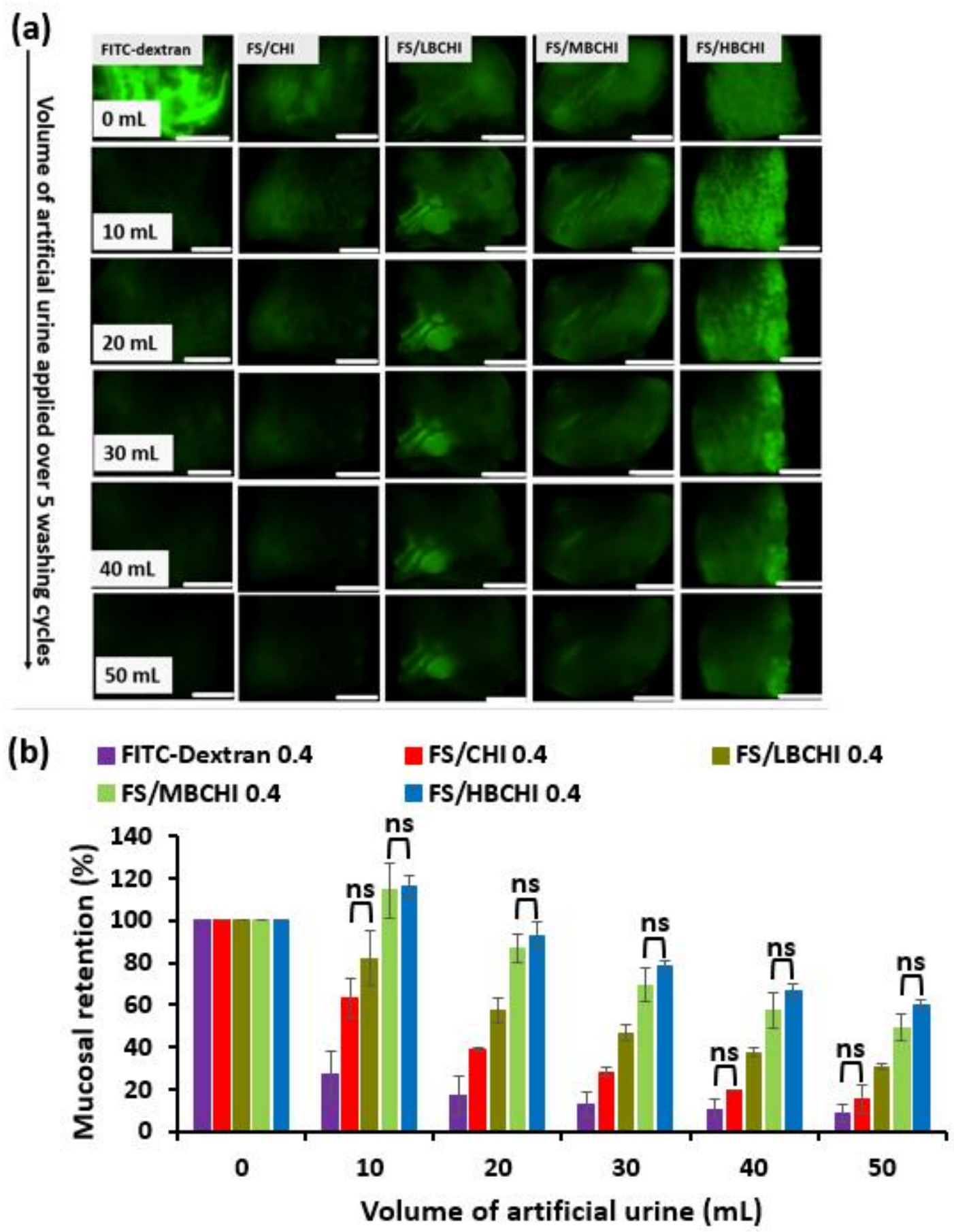

Fig. 6. Ex vivo urine wash-out studies using porcine urinary bladder with fluorescently labelled dextran, $\mathrm{FS} / \mathrm{CHI}, \mathrm{FS} / \mathrm{LBCHI}, \mathrm{FS} / \mathrm{MBCHI}$ and FS/HBCHI. (a) Exemplary fluorescent microscopic photos of the urinary bladder over 5 washing cycles, scale bar represents $2 \mathrm{~mm}$; (b) Mucosal retention of the model drug fluorescein sodium mixed with $\mathrm{CHI}, \mathrm{LBCHI}, \mathrm{MBCHI}$ and $\mathrm{HBCHI}$ at different washing cycles; FITC-dextran served as negative control and $\mathrm{FS} / \mathrm{CHI}$ (unmodified chitosan) as positive control. Results presented as average \pm standard deviation, $n=3$, all the studied groups of samples displayed statistically significant differences between them ( $p<0.05$ ) except those depicted by "ns" implying no significant differences between particular groups of samples. 
It is important to note that the two formulations with better retention (FS/MBCHI and FS/HBCHI) show anomalously brighter images and over $100 \%$ mucosal retention values in the initial wash with $10 \mathrm{~mL}$. This could be related to positive deviations in the fluorescence intensity in this concentration range of sodium fluorescein as reported in Ref. ${ }^{57}$ However, these deviations do not affect the overall result showing greater retention of sodium fluorescein with $\mathrm{MBCHI}$ and $\mathrm{HBCHI}$ formulations.

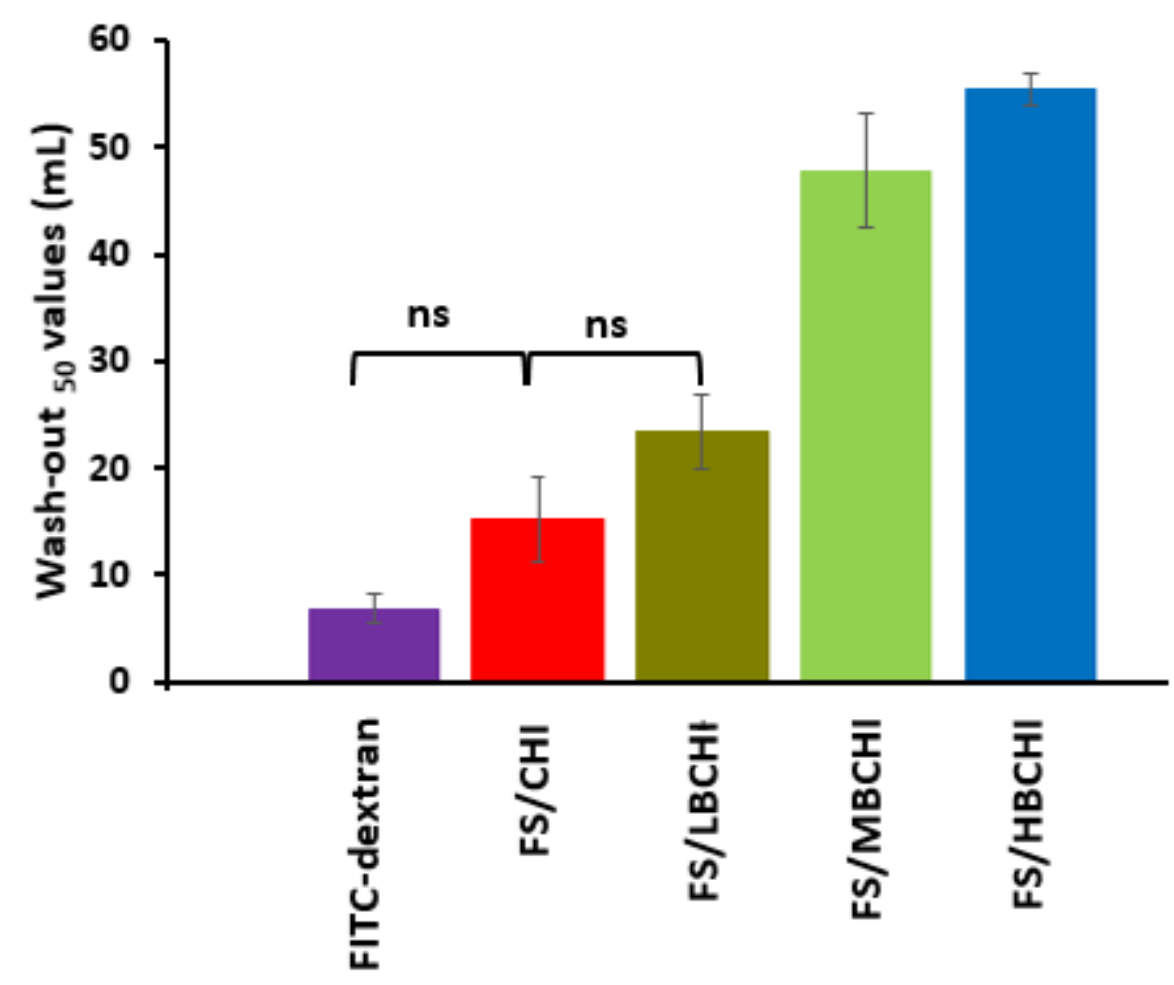

Fig. 7. Urine wash-out 50 values of FITC-dextran, $\mathrm{CHI}, \mathrm{LBCHI}, \mathrm{MBCHI}$ and $\mathrm{HBCHI}$. Results presented as average \pm standard deviation, $n=3$; all the studied groups of samples displayed statistically significant differences between them ( $p<0.05$ ) except those depicted by "ns" implying no significant differences between particular groups of samples.

\subsection{Mucoadhesive properties studied using tensile test}

The force of detachment or adhesive strength indicates the force required to overcome the adhesive bonds between the drug carrier and bladder mucosa, while the work of adhesion is the area under the force-distance curves. 

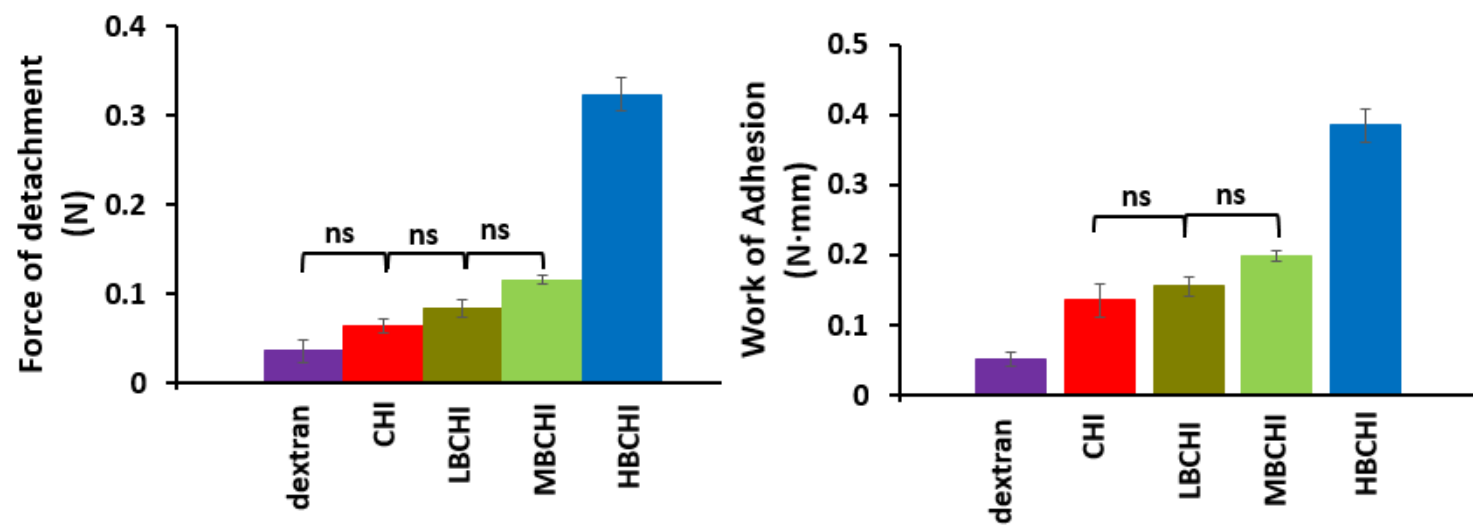

Fig. 8. (a) Force of detachment and (b) work of adhesion of dextran, CHI, LBCHI, MBCHI and HBCHI to porcine bladder mucosa measured using tensile test. Results presented as mean \pm standard deviation, $\mathrm{n}$ $=3$; all the studied groups of samples displayed statistically significant differences between them $(p<$ 0.05) except those depicted by "ns" implying no significant differences between particular groups of samples.

Though, dextran and $\mathrm{CHI}$ displayed similar force of detachment (Fig. 8), the work of adhesion values showed that $\mathrm{CHI}$ was statistically more mucoadhesive than dextran. $\mathrm{MBCH}$ and $\mathrm{HBCH}$ were significantly more mucoadhesive compared to the unmodified chitosan with the force of detachment in increasing order from dextran $(0.04 \pm 0.01 \mathrm{~N})<\mathrm{CHI}(0.06 \pm 0.01 \mathrm{~N})<\mathrm{LBCHI}$ $(0.08 \pm 0.01 \mathrm{~N})<\mathrm{MBCHI}(0.12 \pm 0.01 \mathrm{~N})<\mathrm{HBCHI}(0.32 \pm 0.02 \mathrm{~N})$. CHI vs LBCHI; LBCHI vs MBCHI and $\mathrm{MBCHI}$ vs $\mathrm{HBCHI}$ displayed comparable forces of detachment and work of adhesion values. The work of adhesion presented in increasing order: $\mathrm{CHI}(0.14 \pm 0.02 \mathrm{~N} \cdot \mathrm{mm})<\mathrm{LBCHI}(0.16 \pm 0.02$ $\mathrm{N} \cdot \mathrm{mm})<\mathrm{MBCHI} 0.2 \pm 0.01 \mathrm{~N} \cdot \mathrm{mm}<\mathrm{HBCHI}(0.4 \mathrm{~N} \pm 0.02 \mathrm{~N} \cdot \mathrm{mm})$. Overall, the adhesive strength of the polymers correlated well with their work of adhesion as $\mathrm{MBCHI}$ and $\mathrm{HBCHI}$ exhibited greater force of detachment and work of adhesion relative to the parent chitosan. Though dextran and $\mathrm{CHI}$ displayed similar force of detachment, the work of adhesion values showed that $\mathrm{CHI}$ was statistically more mucoadhesive than dextran. These findings inferred that the mucoadhesiveness of the polymers was improved with increased extent of boronation. This is in good agreement with the urine-wash-out test data. 


\section{Conclusions}

Chitosan boronation had a profound influence on the mucoadhesiveness of the new polymers as their mucoadhesive properties (in terms of wash-out ${ }_{50}$ profile, force of adhesion/detachment and work of adhesion) were greatest for the highly boronated chitosan. This makes boronated derivatives of chitosan promising as mucoadhesive excipients for formulating dosage forms not only for intravesical drug delivery but also for applications in other mucosal routes of drug administration.

\section{Acknowledgements}

The authors are grateful to the Chemical Analysis Facility, University of Reading for providing access to ${ }^{1} \mathrm{H}$ NMR, FT-IR spectroscopies as well as $\mathrm{x}$-ray diffraction. Mr. Nicholas Spencer is appreciated for his assistance with $\mathrm{X}$-ray diffraction analysis. OMK acknowledges the Leche Trust and Gilchrist Educational Trust for financial support of this research. We are also grateful to Dr Brett Symonds for assisting with GPC analysis of the chitosan sample.

\section{References}

1. Torre LA, Bray F, Siegel RL, Ferlay J, Lortet-tieulent J, Jemal A. Global Cancer Statistics, 2012. CA Cancer J Clin. 2015;65(2):87-108.

2. Antoni S, Ferlay J, Soerjomataram I, Znaor A, Jemal A, Bray F. Bladder Cancer Incidence and Mortality: A Global Overview and Recent Trends. Eur Urol. 2017;71(1):96-108.

3. Babjuk M. Trends in Bladder Cancer Incidence and Mortality: Success or Disappointment? Eur Urol. 2017;71(1):109-110.

4. Jayakumar R, Menon D, Manzoor K, Nair S V., Tamura H. Biomedical applications of chitin and chitosan based nanomaterials - A short review. Carbohydr Polym. 2010;82(2):227232.

5. Bernkop-Schnürch A, Dünnhaupt S. Chitosan-based drug delivery systems. Eur J Pharm Biopharm. 2012;81(3):463-469.

6. Casettari L, Illum L. Chitosan in nasal delivery systems for therapeutic drugs. J Control Release. 2014;190:189-200. 
7. Bernkop-Schnürch et al. 1999. Synthesis and in vitro evaluation of chitosan-cysteine conjugates. Sci Pharm. 1999;67:196-208.

8. Kast CE, Bernkop-Schnürch A. Thiolated polymers - thiomers: Development and in vitro evaluation of chitosan-thioglycolic acid conjugates. Biomaterials. 2001;22(17):23452352.

9. Bernkop-Schnürch A. Thiolated polymers-thiomers: synthesis and in vitro evaluation of chitosan-2-iminothiolane conjugates. Int J Pharm. 2003;260(2):229-237.

10. Kafedjiiski K, Föger F, Werle M, Bernkop-Schnürch A. Synthesis and in vitro evaluation of a novel chitosan-glutathione conjugate. Pharm Res. 2005;22(9):1480-1488.

11. Schmitz T, Grabovac V, Palmberger TF, Hoffer MH, Bernkop-Schnürch A. Synthesis and characterization of a chitosan-N-acetyl cysteine conjugate. Int J Pharm. 2008;347(12):79-85.

12. Millotti G, Samberger C, Frohlich E, Bernkop-schnurch A. Chitosan- graft -6mercaptonicotinic Acid: Synthesis, Characterization, and Biocompatibility. Biomacromolecules. 2009;10:3023-3027.

13. Kolawole OM, Lau WM, Khutoryanskiy V V. Methacrylated chitosan as a polymer with enhanced mucoadhesive properties for transmucosal drug delivery. Int J Pharm. 2018;550(1-2):123-129.

14. Zhang D, Yu G, Long Z, Yang G, Wang B. Controllable layer-by-layer assembly of PVA and phenylboronic acid-derivatized chitosan. Carbohydr Polym. 2016;140:228-232.

15. Cambre JN, Sumerlin BS. Biomedical applications of boronic acid polymers. Polymer (Guildf). 2011;52(21):4631-4643.

16. Li Y, Xiao W, Xiao K, et al. Well-defined, reversible boronate crosslinked nanocarriers for targeted drug delivery in response to acidic $\mathrm{pH}$ values and cis-diols. Angew Chemie - Int Ed. 2012;51(12):2864-2869.

17. Cheng C, Zhang X, Wang Y, Sun L, Li C. Phenylboronic acid-containing block copolymers: Synthesis, self-assembly, and application for intracellular delivery of proteins. New J 
Chem. 2012;36(6):1413-1421.

18. Ma R, Yang $\mathrm{H}$, Li Z, et al. Phenylboronic acid-based complex micelles with enhanced glucose-responsiveness at physiological $\mathrm{pH}$ by complexation with glycopolymer. Biomacromolecules. 2012;13(10):3409-3417.

19. Liu S, Jones L, Gu FX. Development of Mucoadhesive Drug Delivery System Using Phenylboronic Acid Functionalized Poly(D,L-lactide)-b-Dextran Nanoparticles. Macromol Biosci. 2012;12(12):1622-1626.

20. Liu S, Chang CN, Verma MS, et al. Phenylboronic acid modified mucoadhesive nanoparticle drug carriers facilitate weekly treatment of experimentallyinduced dry eye syndrome. Nano Res. 2015;8(2):621-635.

21. Prosperi-Porta G, Kedzior S, Muirhead B, Sheardown H. Phenylboronic-Acid-Based Polymeric Micelles for Mucoadhesive Anterior Segment Ocular Drug Delivery. Biomacromolecules. 2016;17(4):1449-1457.

22. Zheng C, Guo Q, Wu Z, et al. Amphiphilic glycopolymer nanoparticles as vehicles for nasal delivery of peptides and proteins. Eur J Pharm Sci. 2013;49(4):474-482.

23. Li C, Liu Z, Yan X, Lu W, Liu Y. Mucin-controlled drug release from mucoadhesive phenylboronic acid-rich nanoparticles. Int J Pharm. 2015;479(1):261-264.

24. Wu W, Shen J, Li Y, Zhu H, Banerjee P, Zhou S. Specific glucose-to-SPR signal transduction at physiological pH by molecularly imprinted responsive hybrid microgels. Biomaterials. 2012;33(29):7115-7125.

25. Zhang C, Losego MD, Braun P V. Hydrogel-based glucose sensors: Effects of phenylboronic acid chemical structure on response. Chem Mater. 2013;25(15):32393250.

26. Wu W, Mitra N, Yan ECY, Zhou S. Multifunctional Hybrid Nanogel for and Self-Regulated Insulin Release at Physiological pH. ACS Nano. 2010;4(8):4831-4839.

27. Wang X, Zhen X, Wang J, Zhang J, Wu W, Jiang X. Doxorubicin delivery to 3D multicellular spheroids and tumors based on boronic acid-rich chitosan nanoparticles. Biomaterials. 
2013;34(19):4667-4679.

28. Wang J, Zhang Z, Wang X, Wu W, Jiang X. Size- and pathotropism-driven targeting and washout-resistant effects of boronic acid-rich protein nanoparticles for liver cancer regression. J Control Release. 2013;168(1):1-9.

29. Wang J, Wu W, Zhang Y, et al. The combined effects of size and surface chemistry on the accumulation of boronic acid-rich protein nanoparticles in tumors. Biomaterials. 2014;35(2):866-878.

30. Lee SY, Lee $\mathrm{H}, \mathrm{In} \mathrm{I}$, Park SY. PH/redox/photo responsive polymeric micelle via boronate ester and disulfide bonds with spiropyran-based photochromic polymer for cell imaging and anticancer drug delivery. Eur Polym J. 2014;57:1-10.

31. Piest $\mathrm{M}$, Ankoné $\mathrm{M}$, Engbersen JFJ. Carbohydrate-interactive pDNA and siRNA gene vectors based on boronic acid functionalized poly(amido amine)s. J Control Release. 2013;169(3):266-275.

32. Ji M, Li P, Sheng N, et al. Sialic Acid-Targeted Nanovectors with Phenylboronic AcidGrafted Polyethylenimine Robustly Enhance siRNA-Based Cancer Therapy. ACS Appl Mater Interfaces. 2016;8(15):9565-9576.

33. Wang X, Wei B, Cheng X, Wang J, Tang R. 3-Carboxyphenylboronic acid-modified carboxymethyl chitosan nanoparticles for improved tumor targeting and inhibitory. Eur J Pharm Biopharm. 2017;113:168-177.

34. Wang X, Tang H, Wang C, Zhang J, Wu W, Jiang X. Phenylboronic acid-mediated tumor targeting of chitosan nanoparticles. Theranostics. 2016;6(9):1378-1392.

35. Asantewaa Y, Aylott J, Burley JC, Billa N, Roberts CJ. Correlating physicochemical properties of boronic acid-chitosan conjugates to glucose adsorption sensitivity. Pharmaceutics. 2013;5(1):69-80.

36. Shitrit Y, Bianco-Peled H. Acrylated chitosan for mucoadhesive drug delivery systems. Int J Pharm. 2017;517(1-2):247-255.

37. Sogias IA, Khutoryanskiy V V., Williams AC. Exploring the factors affecting the solubility 
of chitosan in water. Macromol Chem Phys. 2010;211(4):426-433.

38. Chutipongtanate S, Thongboonkerd V. Systematic comparisons of artificial urine formulas for in vitro cellular study. Anal Biochem. 2010;402(1):110-112.

39. Mun EA, Williams AC, Khutoryanskiy V V. Adhesion of thiolated silica nanoparticles to urinary bladder mucosa: Effects of PEGylation, thiol content and particle size. Int J Pharm. 2016;512(1):32-38.

40. Caló E, Barros JMSD, Fernández-Gutiérrez M, San Román J, Ballamy L, Khutoryanskiy V V. Antimicrobial hydrogels based on autoclaved poly(vinyl alcohol) and poly(methyl vinyl ether-: Alt -maleic anhydride) mixtures for wound care applications. RSC Adv. 2016;6(60):55211-55219.

41. Boateng JS, Pawar H V., Tetteh J. Polyox and carrageenan based composite film dressing containing anti-microbial and anti-inflammatory drugs for effective wound healing. Int J Pharm. 2013;441(1-2):181-191.

42. Khutoryanskiy V V. Advances in Mucoadhesion and Mucoadhesive Polymers. Macromol Biosci. 2011;11(6):748-764.

43. Khutoryanskiy V V. Mucoadhesive Materials and Drug Delivery Systems. John Wiley \& Sons; 2014:33.

44. Ways TM, Lau WM, Khutoryanskiy V V. Chitosan and Its Derivatives for Application in Mucoadhesive Drug Delivery Systems. Polymers (Basel). 2018;10(3):267.

45. Deshayes $\mathrm{S}$, Cabral $\mathrm{H}$, Ishii $\mathrm{T}$, et al. Phenylboronic acid-installed polymeric micelles for targeting sialylated epitopes in solid tumors. J Am Chem Soc. 2013;135(41):15501-15507.

46. Fischer MJ. Amine Coupling Through EDC/NHS: A Practical Approach. de Mol N.; Fisher M., ed. Methods Mol Biol. 2010;627:55-73.

47. Prochazkova S, Vårum KM, Ostgaard K. Quantitative determination of chitosans by ninhydrin. Carbohydr Polym. 1999;38:115-122. 
48. Ince BA, Anderson EJ, Neer RM. Lowering dietary protein to U.S. recommended dietary allowance levels reduces urinary calcium excretion and bone resorption in young women. J Clin Endocrinol Metab. 2004;89(8):3801-3807.

49. GuhaSarkar S, Banerjee R. Intravesical drug delivery: Challenges, current status, opportunities and novel strategies. J Control Release. 2010;148(2):147-159.

50. Alguacil J, Kogevinas M, Silverman DT, et al. Urinary pH, cigarette smoking and bladder cancer risk. Carcinogenesis. 2011;32(6):843-847.

51. Yin J, Luo K, Chen X, Khutoryanskiy V V. Miscibility studies of the blends of chitosan with some cellulose ethers. Carbohydr Polym. 2006;63(2):238-244.

52. Luo K, Yin J, Khutoryanskaya O V., Khutoryanskiy V V. Mucoadhesive and elastic films based on blends of chitosan and hydroxyethylcellulose. Macromol Biosci. 2008;8(2):184192.

53. Sogias IA, Williams AC, Khutoryanskiy $V$. Why is chitosan mucoadhesive? Biomacromolecules. 2008;9(7):1837-1842.

54. Štorha A, Mun E a., Khutoryanskiy V V. Synthesis of thiolated and acrylated nanoparticles using thiol-ene click chemistry: towards novel mucoadhesive materials for drug delivery. RSC Adv. 2013;3(30):12275.

55. Matsumoto A, Cabral H, Sato N, Kataoka K, Miyahara Y. Assessment of Tumor Metastasis by the Direct Determination of Cell-Membrane Sialic Acid Expression. Angew Chemie Int Ed. 2010;49(32):5494-5497.

56. Liu A, Peng S, Soo JC, Kuang M, Chen P, Duan H. Quantum dots with phenylboronic acid tags for specific labeling of sialic acids on living cells. Anal Chem. 2011;83(3):1124-1130.

57. Nichols JJ, King-Smith PE, Hinel EA, Thangavelu M, Nichols KK. The use of fluorescent quenching in studying the contribution of evaporation to tear thinning. Invest Ophthalmol \& Vis Sci. 2012; 53 (9): 5426-5432. 


\section{Data availability}

The research data used in preparation of the manuscript is available upon request from the authors 